\title{
Seasonal variations of vitamin $D$ and its relation to lipid profile in Iranian children and adults
}

\author{
Sakineh Nouri Saeidlou ${ }^{1}$, Davoud Vahabzadeh ${ }^{2 *}$, Fariba Babaei ${ }^{3}$ and Zakaria Vahabzadeh ${ }^{4}$
}

\begin{abstract}
Background: Vitamin D has a multitude of functional properties and acts like a hormone in the body. Its effect on the lipid profile is one of the proposed mechanisms for its relationship with many disorders during its deficiency. But, this relationship is still conflicting and debatable, so this study was conducted to determine the association between serum level of vitamin $D$ and lipid profiles, including serum concentrations of cholesterol, triglyceride (TG), $H D L$, and $L D L$ in healthy subjects.
\end{abstract}

Methods: In this cross-sectional study, 541 volunteers with age of 5-60 years from normal and healthy subjects were selected via random sampling. Demographics and history of daily or weekly sunlight exposures were recorded. Measuring vitamin D was done in two consecutive seasons: winter and summer. Ten milliliters of peripheral venous blood sample was withdrawn after an overnight fasting. Serum levels of $25(\mathrm{OH}) \mathrm{D}(25$, hydroxy vitamin D3) were measured using the enzyme-linked immunosorbent assay (ELISA), and the Confirmatory test was done by highperformance liquid chromatography (HPLC).

Results: Mean age in the total mixed population was $30.83 \pm 14.02$ years. Subjects were $50.5 \%$ male and $49.5 \%$ female. Mean 25(OH) D in the total population for winter and summer were $45.8 \pm 24.26 \mathrm{ng} / \mathrm{ml}$ and $55.24 \pm 37$. $47 \mathrm{ng} / \mathrm{ml}$ respectively. In the total population, $38.08 \%$ were vitamin D deficient. Comparing serum lipid levels in the summer and winter showed a significant difference for cholesterol, LDL, and $H D L$, but no significant effect was found for TG. Analysis for the comparison of lipid profiles between the two genders in winter showed that there were significant differences in all lipid profiles except for LDL, while such analysis for summer revealed significant difference just for TG. In multivariate analysis, there was a significant mean difference only for LDL in subgroups with vitamin D insufficiency and deficiency. There was no correlation between Vitamin D and lipid profiles.

Conclusions: Vitamin D is different between the two seasons regardless of gender variations. Its status showed some significant relationship with some lipid profiles (cholesterol, LDL, and HDL) during the two seasons. There were different results among winter and summer based on the gender.

Keywords: Vitamin D, Lipid profile, Child, Adult, Iran

\footnotetext{
* Correspondence: dvaha2003@yahoo.com

${ }^{2}$ Maternal and Child Obesity Research Center (MCORC), Urmia University of

Medical Sciences, Urmia, Iran

Full list of author information is available at the end of the article
} International License (http://creativecommons.org/licenses/by/4.0/), which permits unrestricted use, distribution, and reproduction in any medium, provided you give appropriate credit to the original author(s) and the source, provide a link to the Creative Commons license, and indicate if changes were made. The Creative Commons Public Domain Dedication waiver (http://creativecommons.org/publicdomain/zero/1.0/) applies to the data made available in this article, unless otherwise stated. 


\section{Background}

Vitamin D acts in the body like a hormone with a multitude of functions. The main source of vitamin D is solar UV radiation, which converts 7-dehydrocholesterol to provitamin D [1]. Dehydrocholesterol is in turn modified to vitamin $\mathrm{D}$ (cholecalciferol) given normal skin temperature. There are few natural dietary sources of vitamin D, which can be found in fatty fish like salmon and herring and in cod liver oil [2].

Serum $25(\mathrm{OH}) \mathrm{D}(25$, hydroxy vitamin $\mathrm{D} 3)$, the recognized biomarker of vitamin $\mathrm{D}$ status best reflects the vitamin D status of the body [3]. Vitamin D deficiency can be defined as vitamin $\mathrm{D}$ serum levels less than $27.5 \mathrm{ng} / \mathrm{ml}$. Vitamin D deficiency is a common disorder, found in all age groups and in both genders [4]. Several mechanisms may be related to $25(\mathrm{OH}) \mathrm{D}$ deficiency and variation in lipid profile, but there is no consensus on the biological plausibility $[5,6]$.

Worldwide, the prevalence of vitamin D deficiency is $50 \%$ in the elderly [7], affecting 30 to $50 \%$ of the adult US population [8] and $20-30 \%$ of the adult European population [9], with increased occurrence in high- and low-latitude countries. In one multi-center osteoporosis study from Iran, the prevalence of mild, moderate, and severe vitamin $\mathrm{D}$ deficiency has been estimated at respectively $47.2,45.7$, and $44.2 \%$ among women and 54.2 , 41.2 , and $37.5 \%$ among men in a $\leq 60$-year-old population $[5,10]$.

From results of cross-sectional data used for metaanalysis where the majority of the study results indicated that serum $25(\mathrm{OH}) \mathrm{D}$ is directly associated with serum HDL-C and inversely related to TC, LDL, and triglyceride (TG), it is important to highlight that higher serum $25(\mathrm{OH}) \mathrm{D}$ is related to a more favorable lipid profile in the pediatric age groups [10].

The relationship between vitamin D status and lipid profile is unclear. Some epidemiological studies suggest an inverse association between circulating levels of $25(\mathrm{OH}) \mathrm{D}$ and cardiovascular risk biomarkers [11, 12], but other studies have not supported the benefit of $25(\mathrm{OH}) \mathrm{D}$ supplementation to improve the blood lipid profile $[13,14]$.

Vitamin D can be affected by environmental factors, such as exposure to ultraviolet light and consumption of foods rich in fat-soluble vitamin D staples (e.g., oily sea fish, meat, and eggs), so repletion of this vitamin's reserves can be done by such factors [12].

Hypovitaminosis D was shown to be associated not only with lowered insulin secretion and sensitivity but also with adverse effects on TG, total cholesterol, and LDL-cholesterol and HDL-cholesterol concentrations in a study of healthy men and women from several racial and ethnic groups [15].

It has been proposed that vitamin $\mathrm{D}$ has a link with different cardiovascular diseases such as HTN, CVD through its different role in endothelial function, blood pressure control, calcification of the coronary vessels, and increased vascular resistance $[5,8,16]$. Also, the effect of vitamin $\mathrm{D}$ on the regulation of the lipid profile is one of the proposed mechanisms for the relationship between vitamin $\mathrm{D}$ deficiency and the abovementioned disorders. The aim of our study is to determine the association between the serum level of vitamin D and lipid profiles, including serum concentrations of cholesterol, TG, HDL, and LDL in the north of Iran in healthy subjects.

\section{Methods}

This cross-sectional study was performed in West Azerbaijan province, a region of the Mediterranean with spring rain at latitude $37^{\circ}$, as a part of a national survey on food and nutrition in the northwest of Iran during winter and summer, 2015. Five hundred and forty-one volunteers with age of 5-60 years from normal and healthy subjects were entered. After dividing the urban area into five different sectors based on socioeconomic status, one health center from each sector was selected randomly. In proportion to the covered child and adult's population in each center, subjects who were eligible for the study were included consequently, after obtaining written consent.

Exclusion criteria were pregnancy, lactation, use of drugs affecting the lipid profile or calcium and bone metabolism, chronic disorders of the liver or kidney, endocrinology disorders such as hypo- or hyperthyroidism and hyperparathyroidism, smoking, insulin injection, use of anticonvulsive drugs, and vitamin D or calcium supplementation.

Demographics and history of daily or weekly sunlight exposures were recorded in the pre-prepared questionnaire. After overnight fasting, $10 \mathrm{ml}$ of peripheral venous blood sample was withdrawn. Blood samples were centrifuged at $3000 \mathrm{rpm}$ for $10 \mathrm{~min}$ and stored at $-20{ }^{\circ} \mathrm{C}$. Serum levels of $25(\mathrm{OH})$ D were measured using the enzyme-linked immunosorbent assay (ELISA), and the confirmatory test was done by high-performance liquid chromatography (HPLC) which measured 25(OH) D. Measurements were done in two consecutive seasons: winter and summer (2014) for the same subjects.

The normal range for $25(\mathrm{OH}) \mathrm{D}$ was considered as 50-75 ng/ml. A 25(OH) D level of lower than $27.5 \mathrm{ng} / \mathrm{ml}$ was considered as vitamin D deficiency, levels between 27.5 and $49.99 \mathrm{ng} / \mathrm{ml}$ considered as insufficient, and levels of equal and more than $50 \mathrm{ng} / \mathrm{ml}$ as sufficient. Plasma total cholesterol, HDL-C, and triglyceride concentrations were measured in duplicate using enzymatic kits, standardized reagents, and standards (Pars Azmoon Co., Tehran, Iran) and autoanalyzer (Selectra E, Vitalab, Holliston, Netherlands). LDL-C concentration was calculated using the Friedewald equation $[13,17]$. 
Table 1 Vitamin D status in two different seasonal categories in summer and winter

\begin{tabular}{llll}
\hline Vitamin D status & $\begin{array}{l}\text { Summer } \\
N(\%)\end{array}$ & $\begin{array}{l}\text { Winter } \\
N(\%)\end{array}$ & $\begin{array}{l}\text { Total } \\
N(\%)\end{array}$ \\
\hline Deficiency & $48(17.70)$ & $158(58.52)$ & $206(38.08)$ \\
Insufficiency & $87(32.12)$ & $78(28.89)$ & $165(30.50)$ \\
Sufficiency & $136(50.18)$ & $34(12.59)$ & $170(31.42)$ \\
Total & $271(100)$ & $270(\% 100)$ & $541(\% 100)$ \\
\hline
\end{tabular}

All continuous values are expressed as mean \pm SD, and categorical variables were presented as a percentage. The independent $t$ test was employed to compare differences between the means of continuous variables between two sexes and the season groups. Multivariate analysis and correlation were performed with data to extract associations between vitamin $\mathrm{D}$ and different above lipid profiles. One-way ANOVA was used for comparing serum vitamin $\mathrm{D}$ and lipid fraction means between three subcategories. Post hoc Tukey test was used for pairwise comparison after ANOVA test. Correlation analysis was recruited for detecting correlations between vitamin $\mathrm{D}$ and lipid profiles in the total population with or without considering the season. $P$ values less than 0.05 were considered statistically significant. Data were analyzed by SPSS statistical software (version 21.0, SPSS Inc.).

\section{Results and discussion}

This cross-sectional study was conducted in the northwest of Iran in population groups with different age ranges from 5 to 60 years old. We studied this target population while considering two age subcategories: $\leq 18$-year-old and $>18$ year-old study populations with two different seasonal categories. Also, another analysis was performed based on sex subgroup classification for different age groups. Mean age in total mixed population was $30.83 \pm 14.02$ years. In the $\leq 18$ years population, mean age was $10.94 \pm 3.21$ years, and for the $>18$ years population, it was $37.89 \pm 8.86$ years. In the less than 18-year-old category, $55.2 \%$ were males and $44.8 \%$ female. In the above-18-year-old category, percentages were 45.8 and $54.2 \%$ respectively. Mean $25(\mathrm{OH}) \mathrm{D}$ in the total population for winter and summer were $45.8 \pm$ $24.26 \mathrm{ng} / \mathrm{ml}$ and $55.24 \pm 37.47 \mathrm{ng} / \mathrm{ml}$ respectively.

The prevalence of vitamin D deficiency in males and females was 6.9 and $27.9 \%$, respectively, and the insufficiency of vitamin D was 28.2 and $35.7 \%$ respectively. Also, the prevalence of vitamin D deficiency in the total studied population was $38.08 \%$ and the overall vitamin $\mathrm{D}$ deficiency and insufficiency according to seasonal categorization were 87.41 and $49.82 \%$ in winter and summer, respectively (Table 1).

In the total population, mean differences between winter and summer for $25(\mathrm{OH}) \mathrm{D}$ were significant $(P<0.001)$. Mean 25(OH) D for the population in winter and summer was $30.96 \pm 24.26 \mathrm{ng} / \mathrm{ml}$ and $55.81 \pm 37.39 \mathrm{ng} / \mathrm{ml}$ respectively (Fig. 1). Also, additional analysis for comparing mean differences between winter and summer for males and females was significant $(P<0.001)$ (Fig. 2$)$.

The current study revealed that differences of average serum levels of lipids in the studied populations in summer and winter were significant for cholesterol, LDL, and HDL, but no significant difference was found for TG. Analysis for comparing lipid profiles between two genders in winter showed that there were significant differences in all lipid profiles except for LDL, while such analysis for summer revealed that there were no significant differences in lipid profiles except for TG (Table 2).

According to the analysis of variances, mean differences for lipid profiles between three groups in different levels of vitamin $\mathrm{D}$ indicated that in subgroups with

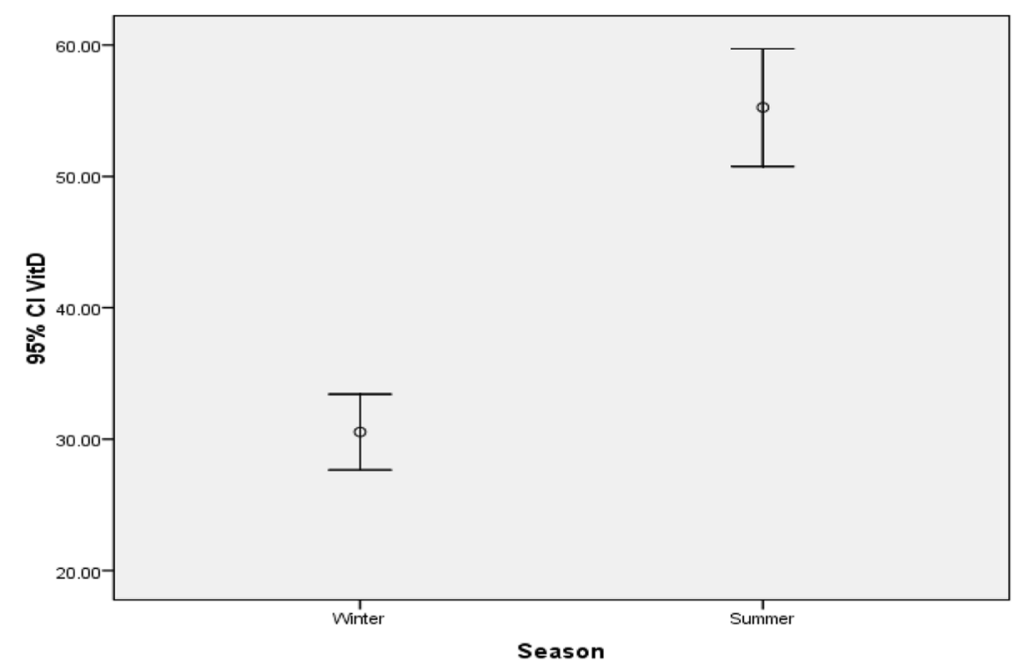

Fig. 1 Comparing mean differences between winter and summer for $25(\mathrm{OH}) \mathrm{D}(P<0.001)$ 


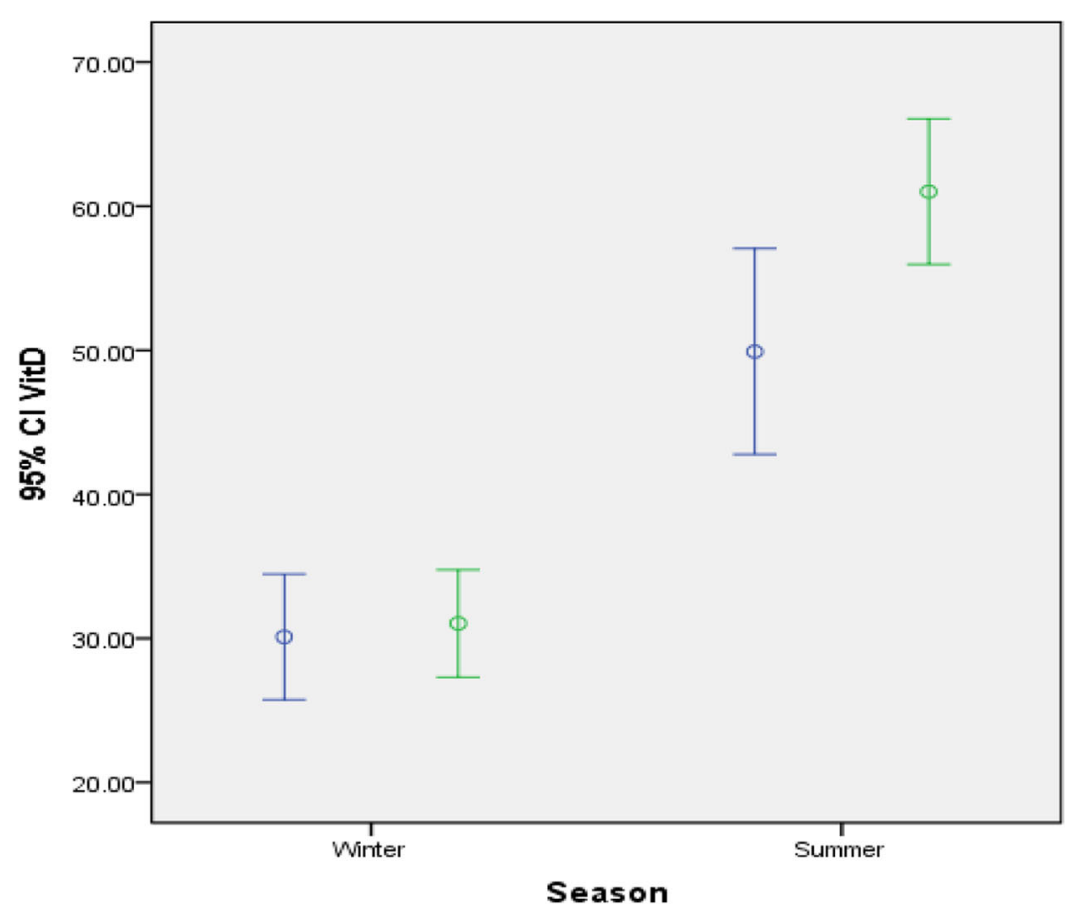

Fig. 2 Comparing mean differences between winter and summer for $25(\mathrm{OH}) \mathrm{D}$ in different sexes $(P<0.001)$

insufficient and deficient levels of vitamin D, there was a significant mean difference only for LDL. Post hoc Tukey test for comparing mean differences are shown in Table 3.

Correlation analysis among study populations is shown in Fig. 3, with no correlation between 25(OH) D and TG, LDL-C, cholesterol, and HDL.

Serum $25(\mathrm{OH})$ D is a well-recognized biomarker of vitamin $\mathrm{D}$ status that best reflects the vitamin $\mathrm{D}$ content of the body [3]. Vitamin D can be affected by environmental factors, such as exposure to ultraviolet light and consumption of foods rich in fat-soluble vitamin D staples (e.g., oily sea fish, meat, and eggs), so repletion of this vitamin's reserves can be done by such factors [12].

This study has established that vitamin D deficiency is more prevalent in the over-18-year-old subgroup but

Table 2 Comparing mean lipid profiles between two genders within different seasons

\begin{tabular}{llllll}
\hline Variable & Sex & $\begin{array}{l}\text { Mean } \pm \text { SD } \\
\text { (winter) }\end{array}$ & $P$ value & $\begin{array}{l}\text { Mean } \pm \text { SD } \\
\text { (summer) }\end{array}$ & $P$ value \\
\hline TG & Female & $108.29 \pm 55.08$ & 0.007 & $116.94 \pm 66.46$ & 0.05 \\
& Male & $158.04 \pm 23.08$ & & $162.24 \pm 258.58$ & \\
CHOL & Female & $159.18 \pm 35.27$ & 0.03 & $172.66 \pm 32.19$ & 0.60 \\
& Male & $167.93 \pm 44.41$ & & $175.11 \pm 45.68$ & \\
LDL & Female & $91.07 \pm 29.02$ & 0.4 & $101.53 \pm 25.78$ & 0.46 \\
& Male & $93.70 \pm 30.06$ & & $99.03 \pm 29.81$ & \\
HDL & Female & $46.42 \pm 10.97$ & 0.016 & $47.73 \pm 11.29$ & 0.08 \\
& Male & $43.17 \pm 14.19$ & & $44.86 \pm 15.56$ & \\
\hline
\end{tabular}

more so in women than in men. Also, vitamin D deficiency was higher in winter than summer. Different studies have reported different values for vitamin D deficiency prevalence. The discrepancies of studies might be partly explained by confounders as age and gender. Similar studies have reported such inequality distribution of vitamin $\mathrm{D}$ deficiency and insufficiency among two different sexes in Asian Indians [18]. However, some reports have established equal distribution between different sexes in Pakistan [19].

Our finding confirmed an inequality of vitamin D deficiency in subjects between two different genders and seasons. This study like other studies [16] reported that seasonal variation in vitamin $\mathrm{D}$ levels can be cited as reasons for overestimation of vitamin D deficiency [20-22], so vitamin D status reporting should be done considering season and gender variations.

Results from studies might be confounded by studied population heterogeneity and the confounders such as parathyroid hormone (PTH), calcium, physical activity, kidney function, sex, age, sun exposure status, and clothing

Table 3 Post hoc Tukey test results for comparing mean LDL between two different groups based vitamin D status

\begin{tabular}{llll}
\hline & Mean differences & Sig & $\mathrm{Cl}$ \\
\hline Deficiency/insufficiency & 7.76 & 0.02 & $0.93-14.6$ \\
Deficiency/adequacy & 6.00 & 0.09 & $7.8-12.78$ \\
Insufficiency/deficiency & 1.76 & 0.83 & $5.41-8.94$ \\
\hline
\end{tabular}



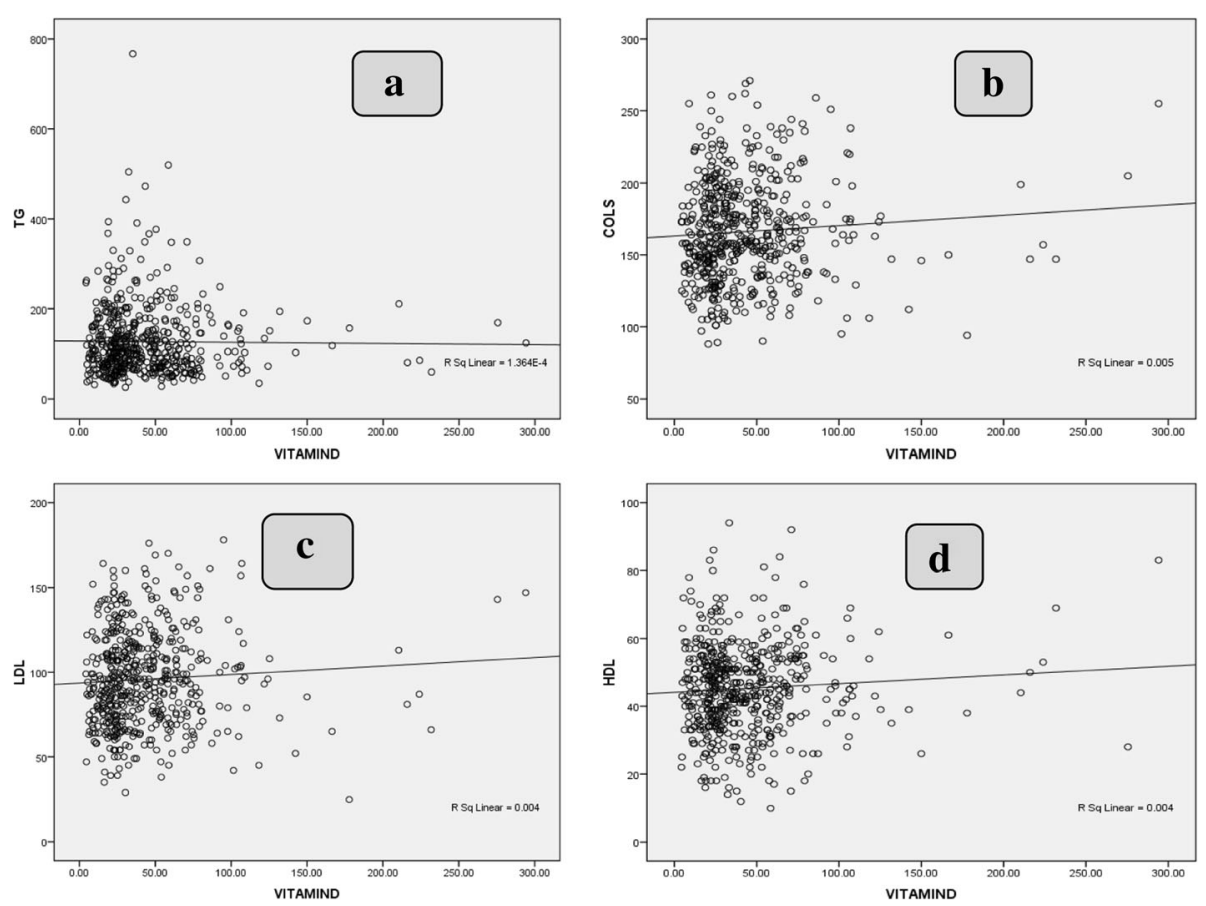

Fig. 3 a Correlation between $25(\mathrm{OH}) \mathrm{D}$ level and triglyceride level $(r=-0.029 ; P=0.638)$. $\mathbf{b}$ Correlation between 25(OH) $\mathrm{D}$ level and cholesterol level $(r=-0.013 ; P=0.826)$. c Correlation between 25(OH) D level and LDL level $(r=-0.015 ; P=0.805) \mathbf{d}$ Correlation between 25(OH) D level and HDL level $(r=0.043 ; P<0.479)$

pattern $[7,10]$. The most reason for seasonal variation may be due to less exposure to the sun in some regions of the world and reduced intake of vitamin D. Also changes in estrogen level with increasing age in women and consequently changes in $\mathrm{Ca}$ and bone metabolism can be related to vitamin $\mathrm{D}$ variation between men and women. Another factor affecting vitamin status and its reduction in females can be women garments in Islamic territories $[3,10]$.

In some studies, the positive effect on lipid profiles has been proposed for vitamin D, but it is not clear whether or not the beneficial effects of vitamin D are due to the hormone itself or its association with calcium metabolism [6, 23]. Calcium acts to form insoluble soaps with dietary fat, preventing its absorption, thus modulating the effect of high dietary fat on blood lipid concentrations [2].

There are different studies with different results and in some instances conflicting results on the relationship between serum levels of vitamin D and lipid profiles. Ford and colleagues, in their NHANES III study, found a negative association between serum levels of $25(\mathrm{OH})$ $\mathrm{D}$ and TG in patients with hypertriglyceridemia, while this relationship was not observed with regard to HDL cholesterol in healthy subjects [24].

In order to determine relationships between $25(\mathrm{OH}) \mathrm{D}$ levels and components of the lipid profile status, average serum levels of lipids in the studied populations in summer and winter were significant for cholesterol, LDL, and HDL, but no significant effect was found for TG. Analysis for comparing lipid profiles between two genders in summer showed that there were significant differences in all lipid profiles except for LDL, while such analysis for winter revealed that there were no significant differences in lipid profiles except for TG.

The possible mechanism for the lowering effect of vitamin $\mathrm{D}$ can be included as the first mechanism; vitamin $\mathrm{D}$ increases serum calcium by enhancing intestinal calcium absorption. This calcium could then reduce serum triglycerides by reducing hepatic triglyceride formation and secretion [25]. The second mechanism is that vitamin D has a suppressive effect on serum PTH concentration. When heparin lipolytic activity decreased by increased PTH concentration, a lowered level of PTH may reduce serum triglycerides by increasing peripheral uptake. In addition to the above mechanisms, other mechanisms have been implicated. Vitamin D may regulate triglycerides metabolism through of increased expression of VLDL cholesterol gene receptors [6]. Another possible mechanism to explain the association between $25(\mathrm{OH}) \mathrm{D}$ and triglycerides would be through insulin resistance: when vitamin $\mathrm{D}$ deficiency is present, the risk of insulin resistance increases and this is associated with an elevation of levels of VLDL cholesterol and triglycerides [26].

In some cross-sectional studies, an association between an increase in vitamin $\mathrm{D}$ level and a decline in LDL, 
cholesterol, and TG and an increase in HDL have been proposed [5, 6, 13, 14, 27], and so far, intervention trials have not clarified the relationship between serum lipids and vitamin D-calcium supplementation for improving lipid profiles $[13,28]$.

In the Kelishadi review [10], inverse weak significant association between $25(\mathrm{OH}) \mathrm{D}$ and triglycerides, total cholesterol, and LDL-C and direct association with HDL-C was showed, but in the Jorde and Grimnes review [15], five of the seven papers reported positive associations of vitamin D level with LDL but only one being statistically significant, while three reported negative associations, with one being significant.

A meta-analysis by Wang et al. observed a slight effect of vitamin D supplementation on LDL, but no effect on TC, HDL, or TG [11].

Our result-based correlation analysis showed that there was no correlation between vitamin D and any of the lipid profile parameters. In other studies such as Johnson et al. and Rusconi et al. [20, 29], such results have been presented where there were no statistically significant correlations between $25(\mathrm{OH})$ D levels and total serum cholesterol. But in the Rajakumar et al. study, there were positive correlations between plasma $25(\mathrm{OH}) \mathrm{D}$ and HDL cholesterol in black and white children [3].

One of the limitations of this study was the lack of dietary intake and physical activity assessment besides the evaluation of serum levels of vitamin D. Another limitation in this study was its implementation just for an urban area since those who live in rural areas can benefit from higher physical activity and sun exposure.

\section{Conclusions}

This study showed that serum levels of vitamin D can be different in the two seasons regardless of gender variations. Also, its association with a lipid profile is still conflicting and debatable. To find the true relationship between vitamin D status and lipid profile, alongside with full control of confounding factors, group synchronization in randomized controlled trials is recommended.

\section{Abbreviations}

25(OH) D: 25, hydroxy vitamin D3; CVD: Cerebrovascular disease; ELISA: Enzyme-linked immunosorbent assay; HDL: High-density lipoprotein; HPLC: High-performance liquid chromatography; LDL: Low-density lipoprotein; NHANES III: National Health and Nutrition Examination Survey III; PTH: Parathyroid hormone; TG: Triglyceride

\section{Acknowledgements}

The authors would like to thank all respected experts in the health departments of Urmia University of Medical Sciences and other individuals who had sincere cooperation in conducting this study in the Ministry of Education in West Azerbaijan.

\section{Authors' contributions}

SNS was the study designer and program manager. DV has participated in the data handling and analysis, the result, and full manuscript preparation. FB has participated in executive management for data collection, sampling, and laboratory test work coordination. ZV has participated in assessing the laboratory-used methods, statistical data analysis evaluation, scientific evaluation, and editing. All authors have seen and approved the final manuscript that has been submitted.

\section{Competing interests}

The authors declare that they have no competing interests.

\section{Consent for publication}

Not applicable.

\section{Ethics approval and consent to participate}

This study was approved by the ethic committee from the deputy of research and technology in Urmia University of Medical Sciences (UMSU), and all participants filled out the consent form.

\section{Publisher's Note}

Springer Nature remains neutral with regard to jurisdictional claims in published maps and institutional affiliations.

\section{Author details}

${ }^{1}$ Food and Beverages Safety Research Center, Urmia University of Medical Sciences, Urmia, Iran. ${ }^{2}$ Maternal and Child Obesity Research Center (MCORC), Urmia University of Medical Sciences, Urmia, Iran. ${ }^{3}$ Deputy of Health, Urmia University of Medical Sciences, Urmia, Iran. ${ }^{4}$ Liver \& Digestive Research Center, Kurdistan University of Medical Sciences, Sanandaj, Iran.

Received: 31 May 2016 Accepted: 11 May 2017

Published online: 22 May 2017

\section{References}

1. Jorde R, Grimnes G. Vitamin D and metabolic health with special reference to the effect of vitamin D on serum lipids. Prog Lipid Res. 2011;50(4):303-12.

2. Steger FL. Associations between vitamin D status and blood lipid parameters in healthy, older adults. 2013.

3. Rajakumar K, de Las HJ, Chen TC, Lee S, Holick MF, Arslanian SA. Vitamin D status, adiposity, and lipids in black American and Caucasian children. J Clin Endocrinol Metabol. 2011;96(5):1560-7.

4. Delvin EE, Lambert M, Levy E, O'Loughlin J, Mark S, Gray-Donald K, et al. Vitamin D status is modestly associated with glycemia and indicators of lipid metabolism in French-Canadian children and adolescents. J Nutr. 2010; 140(5):987-91.

5. Saedisomeolia A, Taheri E, Djalali M, Moghadam AM, Qorbani M. Association between serum level of vitamin $D$ and lipid profiles in type 2 diabetic patients in Iran. J Diabetes Metab Disord. 2014;13(1):1.

6. Chaudhuri JR, Mridula KR, Anamika A, Boddu DB, Misra PK, Lingaiah A, et al. Deficiency of 25-hydroxyvitamin D and dyslipidemia in Indian subjects. Journal Lipids. 2013;2013:623420.

7. Pilz S, Marz W, Wellnitz B, Seelhorst U, Fahrleitner-Pammer A, Dimai HP, et al. Association of vitamin D deficiency with heart failure and sudden cardiac death in a large cross-sectional study of patients referred for coronary angiography. J Clin Endocrinol Metabol. 2008;93(10):3927-35.

8. Al Mheid I, Patel R, Murrow J, Morris A, Rahman A, Fike L, et al. Vitamin D status is associated with arterial stiffness and vascular dysfunction in healthy humans. J Am Coll Cardiol. 2011;58(2):186-92.

9. Zakeri H. Vitamin D, deficiency prevalence in summer compared to winter in a city with high humidity and a sultry climate. Women. 2011;94:90.6.

10. Kelishadi R, Farajzadegan Z, Bahreynian M. Association between vitamin D status and lipid profile in children and adolescents: a systematic review and meta-analysis. Int J Food Sci Nutr. 2014;65(4):404-10.

11. Wang $H$, Xia N, Yang Y, Peng D-Q. Influence of vitamin D supplementation on plasma lipid profiles: a meta-analysis of randomized controlled trials. Lipids Health Dis. 2012;11(1):1.

12. John WG, Noonan K, Mannan N, Boucher BJ. Hypovitaminosis D is associated with reductions in serum apolipoprotein Al but not with fasting lipids in British Bangladeshis. Am J Clin Nutr. 2005;82(3):517-22. 
13. Ponda MP, Huang XX, Odeh MA, Breslow JL, Kaufman HW. Vitamin D may not improve lipid levels: a serial clinical laboratory data study. Circulation. 2012;126(3):270-7.

14. Rajpathak SN, Xue X, Wassertheil-Smoller S, Van Horn L, Robinson JG, Liu S, et al. Effect of $5 \mathrm{y}$ of calcium plus vitamin $\mathrm{D}$ supplementation on change in circulating lipids: results from the Women's Health Initiative. Am J Clin Nutr. 2010;91(4):894-9.

15. Grimnes G, Figenschau Y, Almås B, Jorde R. Vitamin D, insulin secretion, sensitivity, and lipids result from a case-control study and a randomized controlled trial using hyperglycemic clamp technique. Diabetes. 2011;60(11): 2748-57.

16. Alam U, Najam O, Al-Himdani S, Benoliel S, Jinadev P, Berry J, et al. Marked vitamin $D$ deficiency in patients with diabetes in the UK: ethnic and seasonal differences and an association with dyslipidemia. Diabet Med. 2012;29(10):1343-5.

17. Choi HS, Kim K-A, Lim C-Y, Rhee SY, Hwang Y-C, Kim KM, et al. Low serum vitamin $D$ is associated with high risk of diabetes in Korean adults. J Nutr. 2011;141(8):1524-8.

18. Vupputuri MR, Goswami R, Gupta N, Ray D, Tandon N, Kumar N. Prevalence and functional significance of 25-hydroxyvitamin D deficiency and vitamin D receptor gene polymorphisms in Asian Indians. Am J Clin Nutr. 2006; 83(6):1411-9.

19. Sheikh A, Saeed Z, Jafri SAD, Yazdani I, Hussain SA. Vitamin D levels in an asymptomatic adults-a population survey in Karachi, Pakistan. PloS one. 2012;7(3):e33452.

20. Johnson MD, Nader NS, Weaver AL, Singh R, Kumar S. Relationships between 25-hydroxyvitamin D levels and plasma glucose and lipid levels in pediatric outpatients. J Pediatr. 2010;156(3):444-9. e1.

21. Rejnmark $L$, Vestergaard $P$, Heickendorff $L$, Mosekilde L. Simvastatin does not affect vitamin $D$ status, but low vitamin $D$ levels are associated with dyslipidemia: results from a randomized, controlled trial. International journal of endocrinology. 2009;2010:Article ID 957174, 6 pages. doi:10.1155/ 2010/957174

22. Toxqui L, Blanco-Rojo R, Wright I, Pérez-Granados AM, Vaquero MP. Changes in blood pressure and lipid levels in young women consuming a vitamin Dfortified skimmed milk: a randomized controlled trial. Nutrients. 2013;5(12): 4966-77.

23. Qin XF, Zhao LS, Chen WR, Wang H. Effects of vitamin D on plasma lipid profiles in statin-treated patients with hypercholesterolemia: a randomized placebo-controlled trial. Clin Nutr. 2015;34(2):201-6.

24. Ford ES, Ajani UA, McGuire LC, Liu S. Concentrations of serum vitamin D and the metabolic syndrome among US adults. Diabetes Care. 2005;28(5): $1228-30$.

25. Martins D, Wolf M, Pan D, Zadshir A, Tareen N, Thadhani $R$, et al. Prevalence of cardiovascular risk factors and the serum levels of 25 -hydroxyvitamin $\mathrm{D}$ in the United States: data from the Third National Health and Nutrition Examination Survey. Arch Intern Med. 2007;167(11):1159-65.

26. Ginsberg HN, Zhang Y-L, Hernandez-Ono A. Regulation of plasma triglycerides in insulin resistance and diabetes. Arch Med Res. 2005;36(3):232-40.

27. Karhapää P, Pihlajamäki J, Pörsti I, Kastarinen M, Mustonen J, Niemelä O, et al. Diverse associations of 25-hydroxyvitamin D and 1, 25-dihydroxy-vitamin D with dyslipidaemias. J Intern Med. 2010;268(6):604-10.

28. Andersen R, Brot C, Mejborn H, Mølgaard C, Skovgaard LT, Trolle E, et al. Vitamin D supplementation does not affect serum lipids and lipoproteins in Pakistani immigrants. Eur J Clin Nutr. 2009;63(9):1150-3.

29. Rusconi RE, De Cosmi V, Gianluca G, Giavoli C, Agostoni C. Vitamin D insufficiency in obese children and relation with lipid profile. Int J Food Sci Nutr. 2015;66(2): $132-4$.

\section{Submit your next manuscript to BioMed Central and we will help you at every step:}

- We accept pre-submission inquiries

- Our selector tool helps you to find the most relevant journal

- We provide round the clock customer support

- Convenient online submission

- Thorough peer review

- Inclusion in PubMed and all major indexing services

- Maximum visibility for your research

Submit your manuscript at www.biomedcentral.com/submit

C) Biomed Central 